\title{
Labyrinthe
}

40 | 2013

Comme les abeilles

\section{Pourquoi nous ne sommes pas tout à fait des abeilles}

\section{Stéphane Legrand}

\section{OpenEdition}

1 Journals

Édition électronique

URL : http://journals.openedition.org/labyrinthe/4315

DOI : $10.4000 /$ labyrinthe.4315

ISSN : 1950-6031

Éditeur

Hermann

Édition imprimée

Date de publication : 1 mars 2013

Pagination : 71-74

ISBN : 9782705688400

\section{Référence électronique}

Stéphane Legrand, «Pourquoi nous ne sommes pas tout à fait des abeilles », Labyrinthe [En ligne],

40 | 2013, mis en ligne le 01 mars 2015, consulté le 01 mai 2019. URL : http://

journals.openedition.org/labyrinthe/4315; DOI : 10.4000/labyrinthe.4315

Propriété intellectuelle 


\title{
Pourquoi nous ne sommes pas tout à fait des abeilles
}

\author{
Stéphane LEGRAND
}

« La fixité du contenu », « l'invariabilité du message », le « rapport à une seule situation », « la nature indécomposable de l'énoncé », sa « transmission unilatérale »sont, en résumé, l'ensemble des éléments qui placent le langage des abeilles en dessous du langage humain selon Benveniste. Et de cet ensemble de différences, le linguiste conclut qu'on ne peut pas parler de langage à propos des abeilles, que la radicale spécificité de l'exception humaine doit donc être maintenue sur ce point, et qu'on ne peut parler, au mieux, que d'un code de signaux.

Je conclus moi-même de manière un peu déceptive: il n'y a pas de langage des abeilles, ce dont on était convaincu au départ, mais ce qui est important est le voyage... Bref: l'irréductibilité du langage humain à quelque forme de communication animale que ce soit est incontestable. Elle est d'ailleurs incontestée par les éthologues. Mais ce n'est peut-être pas pour les raisons avancées par Benveniste, et c'est donc avec des conséquences théoriques peut-être différentes: chacun des traits spécifiques du langage humain se retrouve dans un ou plusieurs langages animaux, notamment chez les oiseaux et les singes (étudiés dans la deuxième partie du $\mathrm{Xx}^{\mathrm{e}}$ siècle $^{1}$, la danse des abeilles ayant surtout été étudiée pendant la première partie du siècle). Les abeilles selon le biologiste Haldane prennent des décisions interactives pour choisir l'emplacement d'une ruche, ce qui semble indiquer qu'elles dialoguent, fût-ce à un niveau rudimentaire. Les poules domestiques et les macaques rhésus sont capables de mentir à propos d'une source de nourriture ${ }^{2}$, ce qui indique que leur utilisation de signaux relève d'une intentionnalité et non d'un simple réflexe vital génétiquement codé. Autre cas : les loups

1. Voir «L'éloquence des singes », Labyrinthe, 38, 2012.

2. Voir Ph. Descola, Par-delà nature et culture, Paris, Gallimard, « Bibliothèque des sciences humaines », 2005. 


\section{Labyrinthe, $n^{\circ} 40$}

savent faire des métaphores, remarque Bateson après l'avoir observé au zoo de Chicago (le chef de bande se dirige vers son rival, et lui abaisse la tête avec le museau, quatre fois, ce qui lui signifie son statut d'inférieur de façon métaphorique).

Donc, il n'y a pas de différence essentielle entre langage humain et communications animales : mais s'il ne possède aucun trait en propre, il est le seul à tous les posséder. Au fond, il n'y a pas de propre de l'homme au sens aristotélicien. Mis à part peut-être une chose, ou deux, et que mentionne le biologiste Haldane : dans son article sur la danse des abeilles, il considère que celle-ci doit moins être prise comme la communication d'un état de faits passés ( «j'ai vu du pollen à tel endroit »), que comme inductrice d'une série d'actions futures. Il s'agit moins de communiquer un message que d'exécuter un rite inducteur d'actions futures.

Autrement dit, l'orientation temporelle de la danse des abeilles, si on est rigoureux, est indécidable: du point de vue de la grammaire des abeilles, ça n'aurait pas de sens de l'orienter vers le passé, le présent ou l'avenir. Le langage des abeilles est temporellement indécidable en quelque sorte, ça fait sa spécificité.

Dernière chose, que remarque Dominique Lestel : les animaux semblent incapables de communiquer en troisième personne (les abeilles en tout cas), à propos d'un tiers. L'homme serait donc le seul animal capable de fabuler, de parler à propos de, de parler des actions de quelqu'un d'autre. Il est le seul capable d'écrire une fable des abeilles, alors qu'elles ne seraient pas capables de raconter une fable des hommes. Au fond ça ne les intéresse pas. Elles ont peut-être raison d'ailleurs. Mais s'il y a un propre du langage humain, c'est peut-être qu'il est le seul capable de raconter des histoires. 
66 II y a certes un enseignement pour vous dans les bestiaux : Nous vous abreuvons de ce qui est dans leurs ventres, - [un produit] extrait du [mélange] des excréments [intestinaux] et du sang - un lait pur, délicieux pour les buveurs.

67 Des fruits des palmiers et des vignes, vous retirez une boisson enivrante et un aliment excellent. II y a vraiment là un signe pour des gens qui raisonnent

68 [Et voilà] ce que ton Seigneur révéla aux abeilles: Prenez des demeures dans les montagnes, les arbres, et les treillages que [les hommes] font.

69 Puis mangez de toute espèce de fruits, et suivez les sentiers de votre Seigneur, rendus faciles pour vous. De leur ventre, sort une liqueur, aux couleurs variées, dans laquelle il y a une guérison pour les gens. II y a vraiment là une preuve pour des gens qui réfléchissent.

Le Coran, sourate 16, dite « Sourate des abeilles ». 